$7-10-2000$

\title{
Comment on "Direct Observation of Stretched-Exponential Relaxation in Low-Temperature Lennard-Jones Systems Using the Cage Correlation Function"
}

\author{
Ulrich Zürcher \\ Cleveland State University, u.zurcher@csuohio.edu \\ T. Keyes \\ Boston University
}

Follow this and additional works at: https://engagedscholarship.csuohio.edu/sciphysics_facpub

Part of the Physics Commons

How does access to this work benefit you? Let us know!

Publisher's Statement

(C2000 American Physical Society

\section{Repository Citation}

Zürcher, Ulrich and Keyes, T., "Comment on "Direct Observation of Stretched-Exponential Relaxation in Low-Temperature Lennard-Jones Systems Using the Cage Correlation Function"' (2000). Physics Faculty Publications. 270.

https://engagedscholarship.csuohio.edu/sciphysics_facpub/270

This Article is brought to you for free and open access by the Physics Department at EngagedScholarship@CSU. It has been accepted for inclusion in Physics Faculty Publications by an authorized administrator of EngagedScholarship@CSU. For more information, please contact library.es@csuohio.edu. 


\section{Comment on "Direct Observation of \\ Stretched-Exponential Relaxation in \\ Low-Temperature Lennard-Jones Systems \\ Using the Cage Correlation Function"}

Rabani, Gezelter, and Berne (RGB) report [1] "direct observation" of stretched exponential relaxation of the cage correlation function, which $[2,3]$ describes the motion of atoms out of the first shell of neighbors, in disordered (Lennard-Jones) LJ solids [4]. Their fit is

$$
C_{\text {cage }}(t)=e^{-(\gamma t)^{\beta}},
$$

with $\beta \simeq 1 / 2$. For temperatures $T^{*}=0.5,0.41$, and 0.33 , $\gamma=1.9,0.83$, and $0.43 \mathrm{~ns}^{-1}$, respectively. RGB note that $\beta$ is uncertain since $C_{\text {cage }}(t)$ has decayed only by a single decade on the observed time scale $(7 \mathrm{~ns})$. They derive a static distribution of relaxation rates, $\rho(k)$, and use Zwanzig's theory [5] to obtain diffusion constants $D$ in "reasonable agreement" with simulation.

Single particle hopping and vibrational motion are two distinct mechanisms for cage dynamics. Vibrations are responsible for the rapid ( $<1 \mathrm{ps})$ decay of neighborship lists in glasses [6]. RGB argue that vibrations do not contribute to irreversible changes since for longer times, the cage will reconstitute itself. However, in condensed phases, vibrational lines are homogeneously broadened, typically in the $\mathrm{GHz}$ range. We thus expect the reconstitution of cages to be incomplete on ns time scales even in the absence of hopping, leading to the ansatz,

$$
C_{\text {cage }}(t)=\kappa\left(p e^{-t / \tau_{v}}+e^{-t / \tau_{h}}\right) .
$$

Here, $p$ is the relative weight of the vibrational mechanism and $\kappa$ is chosen to match the two fits at $t=0.1 \mathrm{~ns}$. Equation (2) is an excellent fit,

\begin{tabular}{lccc}
$T^{*}$ & $\tau_{v}(\mathrm{~ns})$ & $\tau_{h}(\mathrm{~ns})$ & $p$ \\
\hline 0.5 & 0.4 & 2.5 & 1.43 \\
0.41 & 0.4 & 3.7 & 0.77 \\
0.33 & 0.4 & 4.8 & 0.45
\end{tabular}

and [cf. Fig. 1] describes $C_{\text {cage }}(t)$ as well as Eq. (1) over the observed time range. Thus, vibrational dynamics gives rise to a fast, $T$-independent $\beta$ process, while the slow, $T$-dependent $\alpha$ process is due to particle hopping, or structural relaxation [7].

Vibrational frequencies are of the order $\mathrm{ps}^{-1}$, so the low hopping rate limit [4] of Zwanzig's theory applies, $D / T^{*} \sim\langle k\rangle$. Since $\langle k\rangle=-d C_{\text {cage }} /\left.d t\right|_{t \rightarrow 0}=$ $\frac{1}{2} \sqrt{\gamma / \mathrm{t}} \rightarrow \infty,\langle k\rangle$ diverges and RGB introduce an upper cutoff $k_{\max }=390 \mathrm{~ns}^{-1}$ so that $\langle k\rangle \sim \sqrt{\gamma k_{\max }}$. Although $C_{\text {cage }}(t)$ is observed on ns time scale, $D$ is determined by hopping rates $\sim \mathrm{ps}^{-1}$. Rates $\sim \mathrm{ns}^{-1}$ yield $D$ which are far too small. RGB's calculations follow our estimate $D / T^{*} \sim \sqrt{\gamma} ;\left(D_{\text {cage }} / T^{*}\right)^{2} / \gamma=1.15,1.26$, and 1.23 at



FIG. 1. A log-log plot of the two fits for $C_{\text {cage }}(t)$. Dashed lines are stretched exponentials, Eq. (1), and full lines are linear superpositions of two exponentials, Eq. (2). The open diamonds are for $T^{*}=0.5$, the open triangles for $T^{*}=0.41$, and the open squares for $T^{*}=0.33$ (data provided by the authors of Ref. [1]). Note that the parameters in Eq. (2) are chosen such that the fits coincide at $t=0.1 \mathrm{~ns}$.

$T^{*}=0.5,0.41$, and 0.33 . However, the theory estimates of $D$ are "in the ballpark" only because of the contribution of rates orders of magnitude faster than the time scale of observation, governed by the adjustable cutoff.

This work has been supported by NSF Grant No. CHE9708055. U.Z. and T.K. thank the authors of the original paper [1] for providing us with the data shown in Fig. 1.

\section{U. Zürcher* and T. Keyes}

Chemistry Department

Boston University

Boston, Massachusetts 02215

Received 24 May 1999; revised manuscript received 27 January 2000

PACS numbers: 66.30.-h, 02.70.Ns, 31.15.Qg, 61.43.Er

*Present address: Physics Department, University of Rhode Island, Kingston, RI 02881.

[1] E. Rabani, J. D. Gezelter, and B. J. Berne, Phys. Rev. Lett. 82, 3649 (1999).

[2] E. Rabani, J. D. Gezelter, and B. J. Berne, J. Chem. Phys. 107, 6867 (1997).

[3] J. D. Gezelter, E. Rabani, and B. J. Berne, J. Chem. Phys. 110, 3444 (1999).

[4] T. Keyes, J. Chem. Phys. 101, 5081 (1994).

[5] R. Zwanzig, J. Chem. Phys. 79, 4507 (1983).

[6] T. Keyes, J. Chem. Phys. 110, 1097 (1999).

[7] W. Götze, in Liquids, Freezing and the Glass Transition, edited by D. Levesque, J.P. Hansen, and J. Zinn-Justin (Elsevier, New York, 1991). 